\title{
The effects of residual organic solvent on epoxy: modeling of kinetic parameters by DSC and Borchardt-Daniels method
}

\author{
Victor de Carvalho Rodrigues ${ }^{1 *}$ (D), Denise Hirayama² (D) and Antonio Carlos Ancelotti Junior ${ }^{3}$ \\ ${ }^{1}$ Núcleo de Inovação em Moldagem e Manufatura Aditiva - NIMMA, Universidade Federal de Santa \\ Catarina - UFSC, Florianópolis, SC, Brasil \\ 'Laboratório de Materiais Poliméricos, Escola de Engenharia Industrial e Metalúrgica de Volta \\ Redonda - EEIMVR, Universidade Federal Fluminense - UFF, Volta Redonda, RJ, Brasil \\ 3Instituto de Engenharia Mecânica - IEM, Universidade Federal de Itajubá - UNIFEI, Itajubá, MG, Brasil \\ *victor_crodrigues@yahoo.com.br
}

\begin{abstract}
The curing reactions of epoxy resins are a complex process that defines thermosets final properties and are affected by any additive present on its formulation. Considering this, the aim of this study was to analyze the influence of the solvent addition on the curing kinetics of an epoxy system. The epoxy samples were prepared using different percentages by weight of acetone: $0,2,5$ and $10 \mathrm{wt} . \%$. From DSC and DMA tests, followed by the Borchardt-Daniels kinetic analysis it was reported that the addition of acetone can decrease the reactions rate, activation energy, $\mathrm{T}_{\mathrm{g}}$ and elastic modulus. The presence of solvent, even in small amounts, can affect the curing mechanisms of epoxy resins. The changes on the curing behavior and the low quality of the final properties for the sample with $10 \mathrm{wt} \%$ of solvent indicates that this may be a limit for acetone addition on the epoxy formulations.
\end{abstract}

Keywords: Acetone, Borchardt-Daniels, curing kinetics, epoxy.

How to cite: Rodrigues, V. C., Hirayama, D., \& Ancelotti Junior, A. C. (2021). The effects of residual organic solvent on epoxy: modeling of kinetic parameters by DSC and Borchardt-Daniels method. Polímeros: Ciência e Tecnologia, 31(1), e2021009. https://doi.org/10.1590/0104-1428.09820

\section{Introduction}

Epoxy resins are defined as a low-molecular-weight prepolymer based on epoxide groups capable to be converted on a thermoset or a three-dimensional network structure ${ }^{[1]}$. This transformation, also known as curing process, occurs due to the reaction between the free epoxide groups and curing agents which causes irreversible changes on the polymer network and will define the final properties of the material ${ }^{[1,2]}$. Due to its great chemical and mechanical properties and versatility, epoxy resins have been deeply studied and are widely used in different industrial fields as adhesives, electronics compounds, coatings and highperformance composite ${ }^{[3,4]}$.

Different formulations are used to improve the epoxy resins properties or to facilitate the manufacturing processes ${ }^{[5]}$. For instance, for composite materials the solvents are generally used to reduce the matrix viscosity and to ease the inclusion of other materials, like fibers or fillers, or even to smooth the processing ${ }^{[6]}$. Nowadays, solvents are also used to recycle fiber composites in order to remove impregnated resins ${ }^{[7,8]}$. The presence of resins must be avoided on recycled fibers since this contamination can reduce the adhesion between fibers and matrix in a later production of other composites ${ }^{[7,9]}$.
Despite the benefits of the solvents in manufacturing processes of epoxy, the presence of this additives, when still present after the curing process, may causes negative changes on thermal and mechanical properties of epoxy systems ${ }^{[10]}$. Loos ${ }^{[11]}$ has studied the influence of acetone on epoxy samples and showed that although its presence reduces the viscosity and facilitates the addition of fillers and nanoparticles, the residual presence of this solvent after the curing process can also decrease some important properties of the material, for instance, the Young's modulus, tensile strength and elongation at break ${ }^{[11]}$. Other studies concluded that the higher the boiling point of the solvent, the greater will be the effect on the curing process. It was also found that the presence of this additives may input barriers to resin/ hardener reaction, decreasing the crosslinking density ${ }^{[6]}$.

In order to achieve suitable properties and also to improve the curing process, it is essential that the formulation and the curing cycle of the material are well defined ${ }^{[12]}$. Using thermal analysis, it is possible to understand the behavior of the curing process and analyze the kinetics of the reaction ${ }^{[13,14]}$.

There are several different methods to study curing kinetics using both dynamic or isothermal tests each with its advantages and limitations. Cole ${ }^{[15]}$ suggested a new 
approach to modeling the curing kinetics of epoxy-amine resins, based on Horie and Kamal methods, but considering the etherification reactions and also the diffusion effects. As a result, the degree of conversion could be calculated with excellent precision over the whole range of cure ${ }^{[15,16]}$. Despite its advantages, this method is based on a complex mathematical approach that still needs to be validated for other epoxy systems as it is less empirical than other conventional models ${ }^{[16]}$. Other studies have also investigated this subject in order to improve the accuracy of the cure kinetic analysis and presented several methods and adaptations that can be used, depending on the purpose of the work ${ }^{[17-19]}$.

Isoconversional methods are capable to evaluate the activation energy $\left(\mathrm{E}_{\mathrm{a}}\right)$ evolution throughout the curing process, while the methods previously mentioned produces only a single value. Hardis et al. ${ }^{[14]}$ have used this model to monitor the curing kinetics of epoxy resins and obtained accurate values for the kinetic parameters. However, this approach is more complex and also require several DSC tests, which can make it difficult to reproduce ${ }^{[14]}$.

The Borchardt-Daniels approach was the first single scan method used to calculate the curing kinetic parameters of epoxy resins, it is one of the simplest methods for modeling the curing reactions and its great advantage is the rapidity to perform the analysis ${ }^{[20,21]}$. This model is based on the relation between the degree of conversion $(\alpha)$, the enthalpy changes and can be applied for $\mathrm{n}^{\text {th }}$ order reactions. Then, based on the enthalpy obtained by dynamic DSC analysis, it is possible to calculate $\alpha$ following the Equation 1, where $\Delta \mathrm{H}_{\mathrm{p}}$ is the partial enthalpy and $\Delta \mathrm{H}_{\mathrm{o}}$ is the total enthalpy (Area under the exothermic peak) ${ }^{[22]}$.

$$
\alpha=\frac{\Delta H_{p}}{\Delta H_{o}}
$$

The analysis is based on the Equation 2, where $\mathrm{d} \alpha / \mathrm{dt}$ is the reactions rate $\left(\mathrm{s}^{-1}\right), \alpha$ is the conversion degree, $k(\mathrm{~T})$ is the velocity constant at temperature $T$ and $n$ is the reaction $\operatorname{order}^{[21]}$.

$$
\frac{d \alpha}{d t}=k(T) \cdot(1-\alpha)^{n}
$$

With this method it is possible to simulate and evaluate some important parameters of the curing process such as activation energy $\left(E_{\mathrm{a}}\right)$, reaction order $(\mathrm{n})$, and degree of conversion $(\alpha)^{[22,23]}$. The Borchardt-Daniels method considers the curing reaction as a single step process and that the $\mathrm{E}_{\mathrm{a}}$ does not change with temperature ${ }^{[20]}$. As a result, the values obtained for the activation energy are dependent on the heating rate and are generally overestimated compared to other kinetic models, such as Ozawa and Kissinger ${ }^{[13,24]}$. Some studies have shown that for higher heating rates, the values of kinetic parameters tend to increase ${ }^{[4,24]}$. However, this method can be very useful as it provides a great overview of the curing kinetics behavior and is recommended when it is necessary to quickly evaluate approximate values of the curing kinetic parameters, since it requires just a single DSC $\operatorname{scan}^{[24]}$.

The literature about epoxy-based composites has mainly explored the changes on the curing mechanisms and epoxy's properties caused by nanoparticles and fillers, with a little regard for the presence of residual solvent as a potential cause of the changes on the materials behavior ${ }^{[25]}$. In addition, it is known that an incomplete curing cycle can affect and reduce the materials final properties ${ }^{[10,25]}$. For these reasons, the aim of this study was to investigate the efficiency of the Borchardt-Daniels methodology to investigate the influence of different amounts of an organic solvent on the curing kinetics of an epoxy resin, generally used for composite materials, to analyze the effects of this additive on the reactions rate and also to evaluate the changes on the material properties, in order to aware about the possible impacts of residual solvent on epoxy composites formulation. A comparison between the curing kinetics parameters obtained by this model and the changes on thermal and mechanical properties of this epoxy system provided a preliminary result that should help to define a critical amount of solvent contamination in these systems and also to propose a useful method to evaluate the curing kinetics of epoxy resins.

\section{Materials and Methods}

\subsection{Materials}

The resin used in this work was the Araldite ${ }^{\circledR}$ LY 5052 , supplied by Huntsman ${ }^{\circledR}$, which is a cold curing low-viscosity resin composed by 1,4-butanediol diglycidyl ether $\left(\mathrm{C}_{10} \mathrm{H}_{18} \mathrm{O}_{4}\right)$ with 55-68 wt.\% composition and an epoxy phenol novolac resin $\left(\mathrm{C}_{35} \mathrm{H}_{32} \mathrm{O}_{4}\right)$ with $38-42$ wt.\% composition. The phenol novolac resin has four epoxide groups, and its molecular weight is $345 \mathrm{~g} / \mathrm{mol}$. The molecular weight of 1,4-butanediol diglycidyl is $202.3 \mathrm{~g} / \mathrm{mol}$ and its functionality is two ${ }^{[26,27]}$. This epoxy system was combined with Aradur ${ }^{\circledR} 5052$, used as a hardener, which is a mixture of polyamines containing IPDA $\left(\mathrm{C}_{10} \mathrm{H}_{22} \mathrm{~N}_{2}\right)$ with 30-60 wt.\% and cycloaliphatic diamine $\left(\mathrm{C}_{15} \mathrm{H}_{30} \mathrm{~N}_{2}\right)$ with 30-60 wt.\% ${ }^{[26]}$. Acetone $\left(\mathrm{Neon}^{\circledR}, 99,5 \%\right.$ purity) was used as organic solvent.

\subsection{Methods}

\subsubsection{Sample preparation}

The samples were mixed through mechanical stirring with the help of a glass rod for 2 minutes at room temperature using the listed epoxy system with different amounts of acetone. The weight ratio of the resin to hardener was 100:38 according to the manufacturer's recommendation ${ }^{[28]}$. Four samples were prepared to each of the tests containing just the resin $(0 \mathrm{wt} . \%)$ and also a mixing with $2 \%, 5 \%$ and $10 \%$ in weight of solvent. The solvent amounts were defined based on the quantities used on other works from literature and also on the percentage generally used in the processing of epoxy-based composites ${ }^{[11,29,30]}$.

\subsubsection{Dynamic Tests}

For dynamic analysis the samples with approximately $5 \mathrm{mg}$ were sealed on aluminum hermetic pans. The equipment (DSC Q20 2151 from TA Instrument ${ }^{\circledR}$ ) was set to run from $0^{\circ} \mathrm{C}$ to $250^{\circ} \mathrm{C}$ using a $5^{\circ} \mathrm{C} / \mathrm{min}$ heating rate and synthetic air atmosphere with $50 \mathrm{~mL} / \mathrm{min}$ flow. 


\subsubsection{Curing Kinetics Modeling}

The kinetic parameters of the curing process were determined using the DSC dynamic data. Based on the Costa (1999) review about curing kinetic methods for epoxy resins, the mathematical approach chosen to analyze the kinetics involved on the curing reactions of the epoxy samples was the Borchardt-Daniels method, that is simpler than other kinetic models, as it allows to calculate the reaction order $(n)$, pre-exponential factor $(A)$ and activation energy $\left(E_{a}\right)$ from one single dynamic DSC run, following the relations described on the ASTM E2041 ${ }^{[22,31]}$. Based on this method, it was possible to understand the curing behavior and evaluate the curing degree $(\alpha)$ of the samples and also the kinetic parameters describe above. For the enthalpy $(\Delta \mathrm{H})$ evaluation it was considered that the solvent completely evaporated and only the weight of the resin and the hardener were taken into account. These results were also used to simulate and define the subsequent isothermal cycles conditions.

\subsubsection{Isothermal Tests}

For the isothermal analysis samples with average $3 \mathrm{mg}$ were carried out to the equipment previously settled at $90^{\circ} \mathrm{C}$ for a cycle during 90 minutes. A subsequent cycle was performed in order to verify the curing degree and glass transition temperature $\left(\mathrm{T}_{\mathrm{g}}\right)$ of the samples. The equipment was cooled to $0^{\circ} \mathrm{C}$ and a second cycle starts with $5^{\circ} \mathrm{C} / \mathrm{min}$ of heating rate until $200^{\circ} \mathrm{C}$.

\subsubsection{DMA}

The samples used on this test were prepared with the solvent content mentioned above and were placed on a silicon mold to shape the specimens with dimensions approximately $(40 \times 12 \times 2.5) \mathrm{mm}$. Based on the BorchardtDaniels kinetic analysis results, a simulation of the curing cycle was performed to define the samples preparation conditions. Then, in order to cure the pieces, they were carried to an oven at $80^{\circ} \mathrm{C}$ for 3 hours, to later be used on tests. The curing cycle was different from that performed on the DSC analysis, in order to ensure that the samples were totally cured and verify the effect of different curing cycles on the behavior of the samples.

The Dynamic-Mechanical Analysis experiments were carried on the DMA SII Seiko ${ }^{\circledR}$ Exstar 6000 using a dual cantilever assembly and bending operation mode with atmosphere air. The frequency adopted was constant $1 \mathrm{~Hz}$, the temperature range was $25^{\circ} \mathrm{C}$ to $150^{\circ} \mathrm{C}$ using $5^{\circ} \mathrm{C} / \mathrm{min}$ as heating rate and $4 \mathrm{~N}$ as maximum stress. The oscillation amplitude was held constant at $25 \mu \mathrm{m}$. The tests were performed in triplicate and the results were used to analyze the glass transition temperature $\left(\mathrm{T}_{\mathrm{g}}\right)$ by the elastic modulus main drop and tangent delta peak.

\section{Results and Discussions}

\subsection{DSC}

In this section, the effects of the solvent addition on epoxy resins were evaluated by thermal analysis. Figure 1 presents the results obtained by dynamic tests on DSC in order to verify curing behavior of the samples and determine if they can be analyzed by the same kinetic model. It can be noticed that the sample without solvent has presented just one exothermic peak due to the crosslinking process caused by the reactions between the oxirane molecules and the hardener. On the other hand, samples containing acetone have shown an endothermic peak between $45^{\circ} \mathrm{C}$ and $60^{\circ} \mathrm{C}$, which corresponds to the boiling temperature region of acetone (approximately $\left.55^{\circ} \mathrm{C}\right)^{[32]}$. Therefore, these endothermic events are related to the evaporation of solvent during the heating, retarding the curing reactions that started at higher temperatures for the samples containing $2 \mathrm{wt} . \%$ and $5 \mathrm{wt} . \%$ of solvent. Another important information is that, for the samples with $0 \mathrm{wt.} \%, 2 \mathrm{wt} . \%$ and $5 \mathrm{wt} . \%$ of solvent, the total enthalpy was similar, but the sample containing $10 \mathrm{wt} . \%$ of solvent has shown a different behavior and its total enthalpy of the curing reaction was really lower than the others $(72 \%$ lower than the sample without solvent) which indicates that, for this amount of solvent, the curing process was deeply affected and the reactions involved may not be the same. In order to compare the reactions rate and the kinetics involved on the curing process it's important to work with systems that presents the same reaction behavior. Therefore, the kinetics involved on the curing process for the sample with $10 \mathrm{wt} . \%$ of solvent cannot be compared with the other samples. Based on these considerations the kinetics analysis of this sample was disregarded.

From data obtained by DSC dynamic tests, the BorchardtDaniels method were used to analyze the kinetics involved on the curing process since this model can be performed from only one DSC dynamic run ${ }^{[33]}$. In order to study kinetics parameters of the curing reactions some considerations must be taken into account. At first, this model can only be applied for dynamic analysis of a $\mathrm{n}^{\text {th }}$ order reaction ${ }^{[22]}$. Based on the Raponi (2017) study about the same epoxy system which has concluded that this resin has a n-order behavior, this method can be used to analyze the kinetics involved on the curing process of this resin ${ }^{[34]}$. Another consideration is that the velocity constant $k(\mathrm{~T})$ is temperature dependent and follows the Arrhenius expression. Therefore, the Equation 2 can also be adapted follow the relation described on the Equation 3, which relates the reactions rate $(\mathrm{d} \alpha / \mathrm{dt})$ with the curing degree $(\alpha)$, reaction order $(n)$, pre-exponential factor

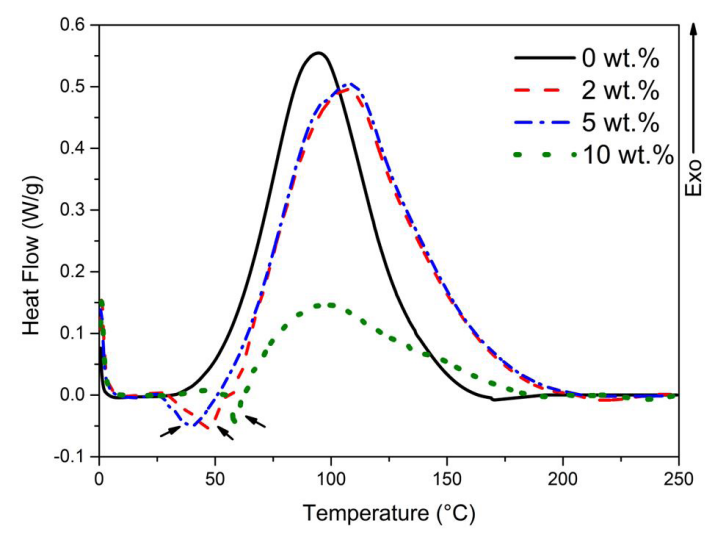

Figure 1. DSC dynamic run for Araldite ${ }^{\circledR}$ LY5052/Aradur ${ }^{\circledR} 5052$ epoxy system with $0,2,5$ and $10 \mathrm{wt} . \%$ of acetone. 
(A), activation energy $\left(\mathrm{E}_{\mathrm{a}}\right)$, the ideal gas constant $(\mathrm{R})$ and the temperature $(\mathrm{T})^{[22,33]}$.

$$
\frac{d \alpha}{d t}=A \cdot e^{\frac{-E_{a}}{R T}} \cdot(1-\alpha)^{n}
$$

As an alternative for the Equation 3, the kinetic parameters can be expressed according to the relations described on the Equation 4 which follows the structure $z=a+b x+c y$, where $\mathrm{z} \equiv \ln (\mathrm{d} \alpha / \mathrm{dt}), \mathrm{x} \equiv \ln (1-\alpha), \mathrm{y} \equiv 1 / \mathrm{T}, \mathrm{a} \equiv \ln \mathrm{A}, \mathrm{b} \equiv \mathrm{n}$ and $\mathrm{c} \equiv-\mathrm{E}_{\mathrm{a}} / \mathrm{R}^{[31]}$. The results from DSC dynamic analysis were used to evaluate the curing rate $(\mathrm{d} \alpha / \mathrm{dt})$ and the conversion degree $(\alpha)$ as function of the temperature (T). Using this data, the Equation 4 can be solved using multiple linear regression in order to calculate some important curing kinetics parameters as reaction order (n), activation energy $\left(\mathrm{E}_{\mathrm{a}}\right)$ and pre-exponential factor $(\mathrm{A})$.

$$
\ln \left(\frac{d \alpha}{d t}\right)=\ln A+n \cdot \ln .(1-\alpha)-\frac{E_{a}}{R T}
$$

The results obtained from the Borchardt-Daniels analysis for the kinetic parameters $\left(A, E_{a}, n\right)$ are described in Table 1 . It is important to notice that all these curing parameters have decreased with the presence of solvent and this reduction was greater for the samples with higher amounts of acetone. It indicates that the volume of these solvents on the resin formulation influences the velocity of the curing process. This behavior is similar to that reported on other works from literature which have concluded that the addition of solvent on epoxy systems can affect the crosslinking mechanisms due to the presence of residual solvent that may difficulty the curing process and decrease the crosslink density, affecting some kinetic parameters such as the reaction order (n) and activation energy $\left(E_{a}\right)^{[6,29,30]}$.

The reaction order (n) is mainly affected by the chemical behavior of the resin, so the reduction of reaction order observed by the addition of the solvent shows changes on the reaction mechanisms of the epoxy system during the curing process, caused by alterations in its formulation ${ }^{[11]}$. Furthermore, the reduction on activation energy $\left(\mathrm{E}_{\mathrm{a}}\right)$ indicates that the acetone can work like a catalytic for curing processing, which does not mean that the reaction rate is higher, as the reaction rate does not depend only on this parameter.

From the Equation 3 is expected that a reduction on the reaction order (n) and the pre-exponential factor (A) decreases the conversion rate $(\mathrm{d} \alpha / \mathrm{dt})$ whereas the activation energy $\left(E_{a}\right)$ has the opposite influence. Due to the contradictions in relation of conversion rate, the influence of theses parameters and the solvent addition on the curing rate were evaluated. Simulations of the evolution of the curing rate as function of the temperature were performed for the different acetone concentrations as exposed in Figure 2. It can be noticed that the maximum value of the conversion rate has decreased with the addition of solvent and also that the curing reactions started at higher temperatures in presence of solvent. These effects were due to the presence of residual solvent which difficult the interactions between the epoxy groups and hardener, reducing the curing rate. The acetone has changed the curing mechanisms in a manner that the reactions rate decreased, this result reveals that the changes on the reaction order and pre-exponential factor have affected the curing process more than the activation energy.

The kinetic parameters described above were used to forecast the curing degree $(\alpha)$, according to the Equation $5^{[35]}$, for the subsequent isothermal tests. From this relation, it is possible to set a temperature (T) and analyze the evolution of the curing degree $(\alpha)$ as function of the reaction time $(t)$. Another approach is to choose the cycle time ( $t)$ of the isothermal run and observe the variation of the curing degree $(\alpha)$ with the temperature $(T)^{[36]}$. Therefore, since many composites are processed under a constant temperature, the first approach was used for the simulation and an isothermal cycle with supposed complete curing degree for all the samples was chosen.

$$
\alpha=1-\left[1-(1-n) \text {.A.t. } \exp \left(\frac{-E a}{R T}\right)\right]^{\left(\frac{1}{1-n}\right)}
$$

In DSC dynamic analysis, at the beginning of the curing process, the reactions are especially fast and disordered, which may difficult to measure the kinetic parameters. On the other hand, at the end of the curing process there are fewer molecular groups available to react, which may

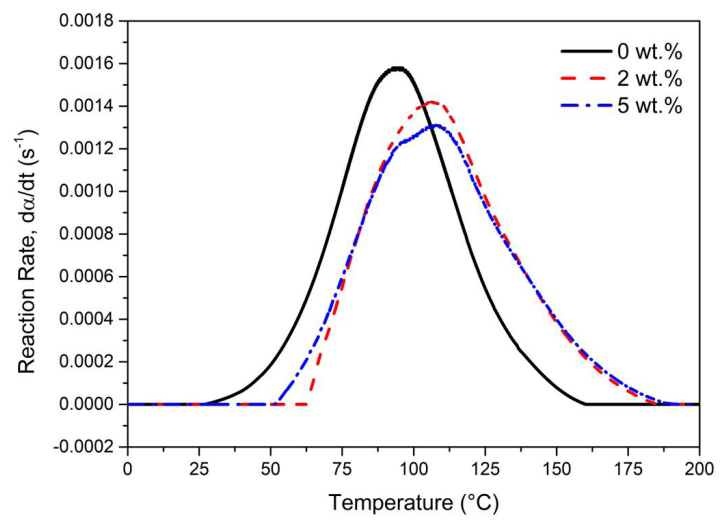

Figure 2. The reaction rate $(\mathrm{d} \alpha / \mathrm{dt})$ evolution with the temperature for the dynamic analysis of Araldite ${ }^{\mathbb{1}} \mathrm{LY} 5052 / \operatorname{Aradur}^{\mathbb{1}} 5052$ epoxy system with $0,2,5$ and $10 \mathrm{wt} . \%$ of acetone.

\begin{tabular}{|c|c|c|c|c|c|c|c|c|}
\hline Sample & $\begin{array}{l}\text { Solvent } \\
\text { wot o }\end{array}$ & $T_{\text {onset }}$ & $T_{\text {máx }}$ & $\begin{array}{l}T_{\text {endset }} \\
\left({ }^{\circ} \mathrm{C}\right)\end{array}$ & $-\Delta \mathbf{H}_{t}$ & $\mathbf{E}_{\mathrm{a}}$ & $\frac{\ln A}{\left(\mathrm{~s}^{-1}\right)}$ & $\mathbf{n}$ \\
\hline & & & & & & & & \\
\hline 1 & 0 & 45.16 & 94.47 & 147.85 & 353.60 & 61.10 & 13.93 & 1.03 \\
\hline 2 & 2 & 60.16 & 106.91 & 180.70 & 321.84 & 37.29 & 5.34 & 0.84 \\
\hline 3 & 5 & 57.34 & 108.07 & 177.10 & 395.79 & 42.75 & 7.06 & 0.91 \\
\hline 4 & 10 & 63.08 & 93.88 & 156.06 & 97.54 & 24.31 & 4.43 & 0.68 \\
\hline
\end{tabular}

Table 1. Kinetics parameters of the Araldite ${ }^{\circledR}$ LY5052/Aradur ${ }^{\circledR} 5052$ epoxy system with $0,2,5$ and 10 wt.\% of acetone obtained by DSC dynamic tests and Borchardt-Daniels analysis. 
not be enough to analyze the kinetics involved. Therefore, isothermal cycle should be defined between the $\mathrm{T}_{\text {onset }}$ and the $\mathrm{T}_{\text {max }}$ of the curing reactions (exothermic peak) in order to improve the kinetic analysis ${ }^{[23]}$. For these reasons, the isothermal run temperature was defined as $90^{\circ} \mathrm{C}$.

From Figure 3, which contains the results for the simulation described above, it can be noticed that the resin without solvent is the first sample to reach the total curing degree (reaction conversion equal 1), followed by the sample with 2 wt.\% of solvent and finally, the sample containing $5 \mathrm{wt} . \%$ of acetone. Therefore, in case of contamination of the resin by solvent, the curing time will take longer as the solvent amount present in the resin increases. According to the simulation, another important consideration is that, after 90 minutes of curing processing at $90^{\circ} \mathrm{C}$, all the samples were completely cured.

As previously mentioned, results of kinetics parameters can only be used to estimate the behavior of resin if the choice of the kinetic method has been made correctly. Through isothermal cycles graphs it is possible to evaluate the reaction order (n) and check if the employed method was appropriated for studied epoxy system. The model, proposed by Borchardt and Daniels, is based in the curing process of $\mathrm{n}$-order reaction that is identified by the exothermic peak at $\mathrm{t} \approx 0$ for isothermal tests. Otherwise, if the maximum heat evolution is located at $30 \%$ and $40 \%$ of the curing time, the reaction can be defined as autocatalytic and could not be evaluated by the Borchardt-Daniels method ${ }^{[22]}$.

In order to verify if the presence of acetone affects the reaction order, some isothermal cycles were performed at $90^{\circ} \mathrm{C}$ during 90 minutes as shown in Figure 4. It can be noticed that the exothermic peak for all the samples is located at the beginning of the isothermal cycle $(t \approx 0)$, which confirms that the curing process of this epoxy system behaves like a Nth order reaction even with the solvent addition.

Since the addition of solvent changes the curing rate of the epoxy system, it was expected that it also affects some important properties of the material - for example, crosslink density. For this reason, some DSC analysis were carried in order to evaluate the changes on the glass transition temperature $\left(\mathrm{T}_{\mathrm{g}}\right)$ of the resin and indirectly estimate alterations in crosslink degree. Figure 5 presents the $T_{g}$ of the samples analyzed by the dynamic cycle performed right after the isothermal analysis. The glass transition temperature found for the epoxy system without solvent was $109^{\circ} \mathrm{C}$, a value close to the one described in the literature ${ }^{[34]}$. For samples containing solvent, the values of $\mathrm{T}_{\mathrm{g}}$ have decreased from $103^{\circ} \mathrm{C}$ for the resin with $2 \mathrm{wt} . \%$ of acetone to $79^{\circ} \mathrm{C}$ for the $10 \mathrm{wt} . \%$. This reduction of $\mathrm{T}_{\mathrm{g}}$ can indicate that the adopted curing cycle for this resin formulation was not appropriated in order to reach the complete cure of epoxy system. It is supposed that the acetone may works as a barrier for the interaction between the epoxy and hardener during the curing process. This barrier effect, caused by the reduction on the availability of reagents in the reaction medium, has contributed with the reduction in reaction rate. Therefore, the curing reaction takes longer to finish in presence of solvent, which means that, for same conditions of reaction, the crosslink density will be lower. This behavior can be verified indirectly by decrease of glass transition temperature ${ }^{[6]}$.
Another important observation is the occurrence of an exothermic event right after the glass transition temperature for the samples with $0 \mathrm{wt} . \%, 2 \mathrm{wt} . \%$ and $5 \mathrm{wt} . \%$ of solvent (highlighted region in Figure 5). These samples were not

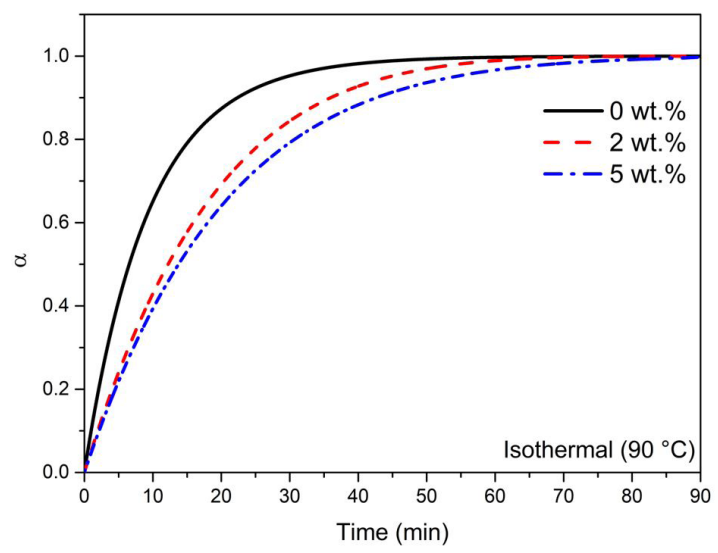

Figure 3. The curing degree $(\alpha)$ forecast for Araldite ${ }^{\circledR}$ LY 5052/ Aradur ${ }^{\mathbb{R}} 5052$ epoxy system as function of time for an isothermal cycle performed at $90^{\circ} \mathrm{C}$.

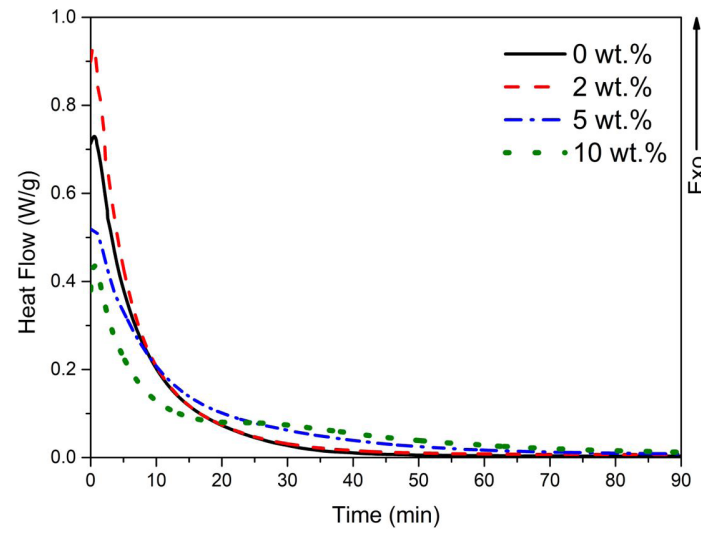

Figure 4. DSC for the isothermal curing cycle performed at $90{ }^{\circ} \mathrm{C}$ during 90 minutes for Araldite ${ }^{\circledR}$ LY5052/Aradur ${ }^{\circledR} 5052$ epoxy system with $0,2,5$ and $10 \mathrm{wt} . \%$ of acetone.

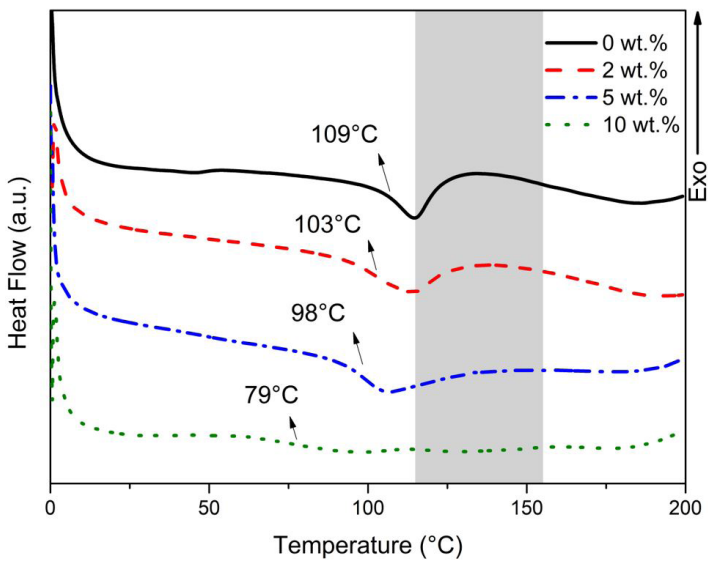

Figure 5. Glass transition temperatures $\left(\mathrm{T}_{\mathrm{g}}\right)$ for Araldite ${ }^{\circledR} \mathrm{LY} 5052$ Aradur ${ }^{\mathbb{R}} 5052$ epoxy system with $0,2,5$ and $10 \mathrm{wt} . \%$ of acetone during the second dynamic run on DSC after the isothermal tests. 
completely cured on the first isothermal run, despite the prediction of the Figure 3, revealing a difference between the results obtained by the Borchardt-Daniels method and the experimental tests. As discussed during this section, the addition of solvent can decrease the conversion rate during the curing reactions of the epoxy system and reduce the final crosslink density.

The sample containing $10 \mathrm{wt} . \%$ of solvent was the only one that did not show the exothermic event after the $\mathrm{T}_{\mathrm{g}}$ on the dynamic run. According to thermal analysis, the sample was completely cured during the isothermal cycle, however the value of $T_{g}$ was much lower than expected. The solvent can produce some low-molecular-weight compounds during its evaporation and reduce the portion of the molecules capable to react during the curing process. These results confirm that the curing mechanisms are deeply affected and produce a different material when large amounts of solvent are present in resin during curing process.

It is important to notice that the Borchardt-Daniels method is not capable to predict these effects and the reductions of the reactions rate ${ }^{[21]}$, so this must be one of the reasons for the difference between the simulation and the tests performed. However, compared to the other methods, which generally needs a series of dynamic and isothermal tests to model the curing kinetics, the Borchardt-Daniels approach is simpler and can investigate the curing kinetics behavior quickly from just one DSC dynamic test, which makes this method attractive despite its limitations to calculate the kinetic parameters absolute values.

\subsection{DMA}

In this section, thermal and mechanical response of the epoxy samples were measured by DMA tests in order to compare the changes on the glass transition temperatures $\left(\mathrm{T}_{\mathrm{g}}\right)$ observed on the DSC analysis and also to verify the mechanical changes caused by the addition of solvent.

According to DSC isothermal analysis, samples with solvent were partially cured, even after the simulation had predicted a complete curing degree (Figure 3), then the curing cycle used to prepare the samples to the DMA tests were different from analyzed on the DSC in order to ensure a complete curing process to all the samples. In previous studies, it is noted that the epoxy system Araldite ${ }^{\circledR}$ LY 5052 that adopted isothermal curing cycle of $80^{\circ} \mathrm{C}$ was totally cured $^{[34]}$, from this information the curing cycle of resin was simulated again by Equation 5 based on isothermal of $80{ }^{\circ} \mathrm{C}$ and the results are shown on Figure 6 .

The simulation demonstrated that all samples reached curing degree of approximately $100 \%(\alpha \cong 1)$ in approximately 140 minutes, for this reason, the curing process for the DMA samples were performed using an isothermal run at $80^{\circ} \mathrm{C}$ during 180 minutes. The time was extended in order to ensure that all the samples were totally cured.

For the analysis of the glass transition temperature changes, the values of the samples $T_{g}$ were measured by both Storage Modulus (E') and Tan $(\delta)$ method as demonstrated in Figure 7. As the DMA measures the viscoelastic response of the material under oscillation load as function of the temperature and the DSC analyzes the energy involved on the process, absolute value obtained for the $\mathrm{T}_{\mathrm{g}}$ from these tests were different ${ }^{[37]}$. Furthermore, the time and temperature adopted for the curing cycle were different for used methods, therefore, the $\mathrm{T}_{\mathrm{g}}$ will not have same values.

Thus, an important analysis is that, despite the difference between the absolute values of the glass transition temperatures, the samples evaluated by the DMA tests have presented a similar behavior as reported by the DSC analysis. The addition of solvent has decreased the $\mathrm{T}_{\mathrm{g}}$ of the epoxy system which was also described by other works ${ }^{[1,25,38]}$.

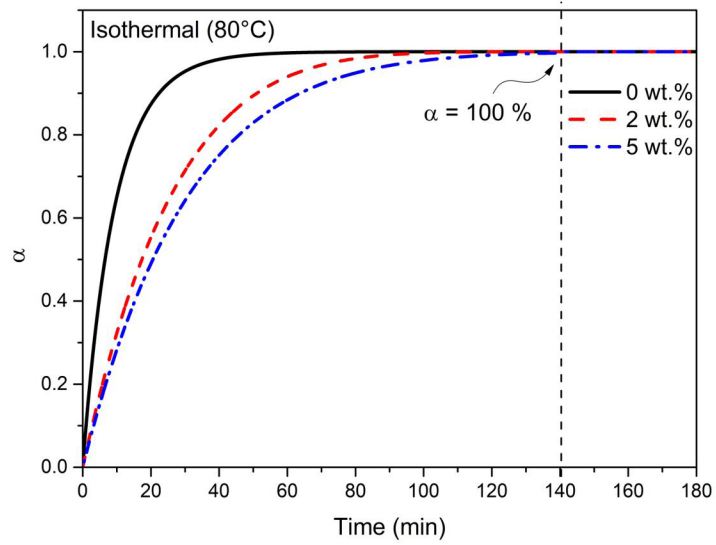

Figure 6. The curing degree $(\alpha)$ forecast for Araldite ${ }^{\circledR}$ LY5052/ Aradur ${ }^{\mathbb{B}} 5052$ epoxy system as function of time for an isothermal cycle performed at $80^{\circ} \mathrm{C}$.

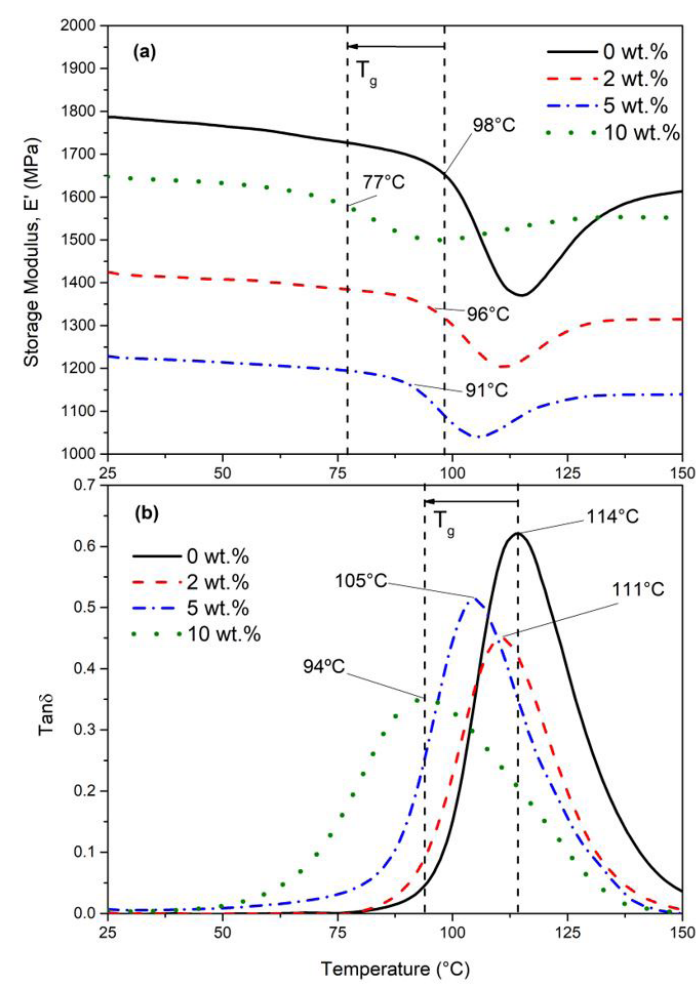

Figure 7. DMA analysis of the glass transition temperature $\left(\mathrm{T}_{\mathrm{g}}\right)$ for Araldite ${ }^{\circledR}$ LY5052/Aradur ${ }^{\circledR} 5052$ epoxy system with 0, 2, 5 and $10 \mathrm{wt} . \%$ of acetone using both methods (a) Storage Modulus (E') as function of temperature (b) $\operatorname{Tan}(\delta)$ as function of temperature. 
From the Figure 7.a, using the Storage Modulus (E') method, it can be noticed that the glass transition temperature $\left(\mathrm{T}_{\mathrm{g}}\right)$ has reduced with the presence of solvent. This behavior is also represented at the Figure 7.b where the $\mathrm{T}_{\mathrm{g}}$ was evaluated by the $\operatorname{Tan}(\delta)$. The glass transition temperature is related with the molecular mobility and depends on the curing degree, so during the curing of thermosetting polymers and after the vitrification process, the crosslink density becomes higher and the mobility is reduced ${ }^{[39]}$. As mentioned before, the presence of solvent can decrease the crosslink density which increases the mobility of the amorphous regions and reduces the glass transition temperature of the resin.

Another important information is that the highest value of storage modulus (E') of the samples has also decreased with the addition of acetone. Loos (2008) has also reported that the presence of these additives may also decreased Young's modulus, tensile strength and elongation at break. These changes are due to the lower crosslink degree caused by the presence of solvent which causes a reduction in mechanical properties ${ }^{[29]}$.

\section{Conclusions}

The effects of acetone addition on the epoxy system Araldite ${ }^{\circledR}$ LY5052/Aradur ${ }^{\circledR} 5052$ properties and its influence on the curing kinetics were studied. The results showed that the presence of this additives decreases the velocity of the curing reactions and are related with the reduction of the $T_{g}$ and storage modulus (E') of the resin. For this reason, the addition of solvent on epoxies formulation should not be disregarded, as it can affect, for example, the curing cycle of composite materials. Furthermore, the epoxy samples containing $10 \mathrm{wt} . \%$ of solvent have presented important changes on the curing mechanisms, so that may be a limit for the acetone addition due to the low quality of the final properties of the resin.

The Borchardt-Daniels analysis have shown a reduction of some important curing parameters such as activation energy $\left(\mathrm{E}_{\mathrm{a}}\right)$, reaction order $(\mathrm{n})$ and pre-exponential factor $(\mathrm{A})$ with the addition of solvent on the epoxy formulation. It is important to notice that this method have some limitations and the values obtained for the kinetic parameters are generally overestimated. However, this model provided a great overview of the behavior of epoxy curing kinetics, from only a single dynamic DSC scan, which allowed to relate the variations of the curing process with the changes in the material properties. There are several other methods that presents a better accuracy for the kinetic parameters, but they are more complex and generally take longer to be performed. Therefore, based on the results of this work, the Borchardt-Daniels method presents a great alternative, simpler and faster than the other kinetic methods, to understand the behavior of the curing reactions and the changes caused by the additives, being a very useful model to define the curing cycle of epoxy resins.

\section{Acknowledgments}

The authors would like to thank the financial support from the Brazilian agency CNPq (Conselho Nacional de Desenvolvimento Científico) for the research funding on the following projects: $307446 / 2020-4,311709 / 2017-6$ and 431219/2018-4.

\section{References}

1. May, C. A. (1988). Epoxy resins: chemistry and technology (2nd edition). Additives for Polymers, 18(5), 19-20. https:// doi.org/10.1016/0306-3747(88)90050-4

2. Mohan, P. (2013). A critical review: the modification, properties, and applications of epoxy resins. Polymer-Plastics Technology and Engineering, 52(2), 107-125. http://dx.doi.org/10.1080/0 3602559.2012 .727057$.

3. Jin, F. L., Li, X., \& Park, S. J. (2015). Synthesis and application of epoxy resins: A review. Journal of Industrial and Engineering Chemistry, 29, 1-11. http://dx.doi.org/10.1016/j.jiec.2015.03.026.

4. Cascaval, C. N., Rosu, D., Mititelu-Mija, A., \& Rosu, L. (2006). Kinetics of the curing reaction of selected epoxy resin-amine systems. Polymers, 51(3), 199-205. http://dx.doi.org/10.14314/ polimery.2006.199.

5. Chen, X. M., \& Ellis, B. (1993). Coatings and other applications of epoxy resins. In B. Ellis (Ed.), Chemistry and technology of epoxy resins (1st ed., pp. 303-0325). Sheffield: Springer Netherlands. http://dx.doi.org/10.1007/978-94-011-2932-9_9

6. Lau, K. T., Lu, M., Lam, C. K., Cheung, H. Y., Sheng, F. L., \& Li, H. L. (2005). Thermal and mechanical properties of single-walled carbon nanotube bundle-reinforced epoxy nanocomposites: The role of solvent for nanotube dispersion. Composites Science and Technology, 65(5 Spe Issue), 719-725. https://doi.org/10.1016/j.compscitech.2004.10.005

7. Okajima, I., Watanabe, K., Haramiishi, S., Nakamura, M., Shimamura, Y., \& Sako, T. (2017). Recycling of carbon fiber reinforced plastic containing amine-cured epoxy resin using supercritical and subcritical fluids. The Journal of Supercritical Fluids, 119, 44-51. http://dx.doi.org/10.1016/j. supflu.2016.08.015.

8. La Rosa, A. D., Banatao, D. R., Pastine, S. J., Latteri, A., \& Cicala, G. (2016). Recycling treatment of carbon fibre/ epoxy composites: materials recovery and characterization and environmental impacts through life cycle assessment. Composites. Part B, Engineering, 104, 17-25. http://dx.doi. org/10.1016/j.compositesb.2016.08.015.

9. Hirayama, D., Saron, C., Botelho, E. C., Costa, M. L., \& Junior, A. C. A. (2017). Polypropylene composites manufactured from recycled carbon fibers from aeronautic materials waste. Materials Research, 20(Suppl. 2), 526-531. http://dx.doi. org/10.1590/1980-5373-mr-2016-1022.

10. Yi, C., Rostron, P., Vahdati, N., Gunister, E., \& Alfantazi, A. (2018). Curing kinetics and mechanical properties of epoxy based coatings: the influence of added solvent. Progress in Organic Coatings, 124(May), 165-174. http://dx.doi.org/10.1016/j. porgcoat.2018.08.009.

11. Loos, M. R., Coelho, L. A. F., Pezzin, S. H., \& Amico, S. C. (2008). The effect of acetone addition on the properties of epoxy. Polimeros, 18(1), 76-80. http://dx.doi.org/10.1590/ S0104-14282008000100015.

12. Costa, M. L., Botelho, E. C., \& Rezende, M. C. (2006). Monitoring of cure kinetic prepreg and cure cycle modeling. Journal of Materials Science, 41(13), 4349-4356. http://dx.doi. org/10.1007/s10853-006-6082-1.

13. Alonso, M. V., Oliet, M., Pérez, J. M., Rodríguez, F., \& Echeverría, J. (2004). Determination of curing kinetic parameters of lignin-phenol-formaldehyde resol resins by several dynamic differential scanning calorimetry methods. Thermochimica Acta, 419(1-2), 161-167. http://dx.doi.org/10.1016/j.tca.2004.02.004.

14. Hardis, R., Jessop, J. L. P., Peters, F. E., \& Kessler, M. R. (2013). Cure kinetics characterization and monitoring of 
an epoxy resin using DSC, Raman spectroscopy, and DEA. Composites. Part A, Applied Science and Manufacturing, 49, 100-108. http://dx.doi.org/10.1016/j.compositesa.2013.01.021.

15. Cole, K. C. (1991). A New Approach to Modeling the Cure Kinetics of Epoxy Amine Thermosetting Resins. 1. Mathematical Development. Macromolecules, 24(11), 3093-3097. http:// dx.doi.org/10.1021/ma00011a011.

16. Cole, K. C., Hechler, J. J., \& Noël, D. (1991). A new approach to modeling the cure kinetics of epoxy Amine Thermosetting Resins. 2. Application to a Typical System Based on Bis[4(diglycidylamino)phenyl]methane and Bis(4-aminophenyl) Sulfone. Macromolecules, 24(11), 3098-3110. http://dx.doi. org/10.1021/ma00011a012.

17. Javdanitehran, M., Berg, D. C., Duemichen, E., \& Ziegmann, G. (2016). An iterative approach for isothermal curing kinetics modelling of an epoxy resin system. Thermochimica Acta, 623, 72-79. http://dx.doi.org/10.1016/j.tca.2015.11.014.

18. Bilyeu, B., Brostow, W., \& Menard, K. (2001). Epoxy thermosets and their applications. III. Kinetic equations and models. The Journal of Materials Education, 23(4-6), 189-204.

19. Kasza, K., Matysiak, L., \& Malinowski, L. (2009). Method to describe curing in large epoxy samples. Advances in Polymer Technology, 28(2010), 267-275. https://doi.org/10.1002/ adv.20162.

20. Borchardt, H. J., \& Daniels, F. (1957). The application of differential thermal analysis to the study of reaction kinetics. Journal of the American Chemical Society, 79(1), 41-46. http:// dx.doi.org/10.1021/ja01558a009.

21. Bogoeva-Gaceva, G., \& Bužarovska,A. (2013). A rapid method for the evaluation of cure kinetics of thermosetting polymers. Macedonian Journal of Chemistry and Chemical Engineering, 32(2), 337-344. http://dx.doi.org/10.20450/mjcce.2013.303.

22. Costa, M. L., Rezende, M. C., \& Pardini, L. C. (1999). Métodos de estudo da cinética de cura de resinas epóxi. Polimeros: Ciência e Tecnologia, 9(2), 37-44. http://dx.doi.org/10.1590/ S0104-14281999000200011.

23. Costa, M. L., Botelho, E. C., De Paiva, J. M. F., \& Rezende, M. C. (2005). Characterization of cure of carbon/epoxy prepreg used in aerospace field. Materials Research, 8(3), 317-322. http://dx.doi.org/10.1590/S1516-14392005000300016.

24. Yang, Z., Peng, H., Wang, W., \& Liu, T. (2010). Crystallization behavior of poly( $\varepsilon$-caprolactone)/layered double hydroxide nanocomposites. Journal of Applied Polymer Science, 116(5), 2658-2667. http://dx.doi.org/10.1002/app.31787.

25. Rivers, G., Rogalsky, A., Lee-Sullivan, P., \& Zhao, B. (2015). Thermal analysis of epoxy-based nanocomposites: have solvent effects been overlooked? Journal of Thermal Analysis and Calorimetry, 119(2), 797-805. http://dx.doi.org/10.1007/ s10973-013-3613-2.

26. Jeyranpour, F., Alahyarizadeh, G., \& Minuchehr, A. (2016). The thermo-mechanical properties estimation of fullerenereinforced resin epoxy composites by molecular dynamics simulation - A comparative study. Polymer, 88, 9-18. http:// dx.doi.org/10.1016/j.polymer.2016.02.018.

27. Eliaz, N., Ron, E. Z., Gozin, M., Younger, S., Biran, D., \& Tal, N. (2018). Microbial degradation of epoxy. Materials (Basel), 11(11), 1-15. http://dx.doi.org/10.3390/ma11112123. PMid:30380643.
28. Huntsman. (2012). Technical Data Sheet - Araldite ${ }^{\circledR} L Y 5052$ / Aradur ${ }^{\circledR} 5052$. Retrieved 2020, June 12, from https://samaro. fr/pdf/FT/Araldite_FT_LY_5052_Aradur_5052_EN.pdf

29. Hong, S. G., \& Wu, C. S. (2000). DSC and FTIR analyses of the curing behavior of epoxy/dicy/solvent systems on hermetic specimens. Journal of Thermal Analysis and Calorimetry, 59(3), 711-719. http://dx.doi.org/10.1023/A:1010189301221.

30. Hong, S. G., \& Wu, C. S. (1998). DSC and FTIR analysis of the curing behaviors of epoxy/DICY/solvent open systems. Thermochimica Acta, 316(2), 167-175. http://dx.doi.org/10.1016/ S0040-6031(98)00356-6.

31. American Society for Testing and Materials - ASTM (2015). 2041 Estimating Kinetic Parameters by Differential Scanning Calorimeter Using the Borchardt and Daniels Method 1. West Conshohocken, PA: ASTM. https://doi.org/10.1520/E204113E01.2

32. Ma, X., Zhang, F., Han, K., Yang, B., \& Song, G. (2015). Evaporation characteristics of acetone-butanol-ethanol and diesel blends droplets at high ambient temperatures. Fuel, 160, 43-49. http://dx.doi.org/10.1016/j.fuel.2015.07.079.

33. Cervi, G., Pezzin, S. H., \& Meier, M. M. (2017). Differential scanning calorimetry study on curing kinetics of diglycidyl ether of bisphenol A with amine curing agents for self-healing systems. Revista Materia, 22(2), 3-8. http://dx.doi.org/10.1590/ s1517-707620170002.0183.

34. Raponi, O. A., Raponi, R. A., Barban, G. B., Benedetto, R. M. D., \& Ancelotti Junior, A. C. (2017). Development of a simple dielectric analysis module for online cure monitoring of a commercial epoxy resin formulation. Materials Research, 20(Suppl. 2), 291-297. http://dx.doi.org/10.1590/1980-5373mr-2017-0067.

35. Costa, M. L., Rezende, M. C., de Paiva, J. M. F., \& Botelho, E. C. (2006). Structural carbon/epoxy prepregs properties comparison by thermal and rheological analyses. PolymerPlastics Technology and Engineering, 45(10), 1143-1153. http://dx.doi.org/10.1080/03602550600887251.

36. de Andrade Raponi, O., Righetti de Souza, B., Miranda Barbosa, L. C., \& Ancelotti, A. C. Jr. (2018). Thermal, rheological, and dielectric analyses of the polymerization reaction of a liquid thermoplastic resin for infusion manufacturing of composite materials. Polymer Testing, 71(July), 32-37. http://dx.doi. org/10.1016/j.polymertesting.2018.08.024.

37. Carbas, R. J. C., Marques, E. A. S., Da Silva, L. F. M., \& Lopes, A. M. (2014). Effect of cure temperature on the glass transition temperature and mechanical properties of epoxy adhesives. The Journal of Adhesion, 90(1), 104-119. http:// dx.doi.org/10.1080/00218464.2013.779559.

38. Le Craz, S., \& Pethrick, R. A. (2011). Solvent effects on cure 1-benzyl alcohol on epoxy cure. International Journal of Polymeric Materials and Polymeric Biomaterials, 60(7), 441-455. http://dx.doi.org/10.1080/00914037.2010.531813.

39. Montserrat, S., \& Cima, I. (1999). Isothermal curing of an epoxy resin by alternating differential scanning calorimetry. Thermochimica Acta, 330(1-2), 189-200. http://dx.doi. org/10.1016/S0040-6031(99)00033-7.

Received: Nov. 05, 2020

Revised: Mar. 21, 2021

Accepted: Mar. 22, 2021 